\title{
Parenting Narcissus: What Are the Links Between Parenting and Narcissism?
}

\author{
Robert S. Horton, Geoff Bleau, and \\ Brion Drwecki
}

Wabash College

\begin{abstract}
Previous theorizing by clinical psychologists suggests that adolescent narcissism may be related to parenting practices (Kernberg, 1975; Kohut, 1977). Two studies investigated the relations between parenting dimensions (i.e., warmth, monitoring, and psychological control) and narcissism both with and without removing from narcissism variance associated with trait self-esteem. Two hundred and twenty-two college students (Study 1) and 212 high school students (Study 2) completed the Narcissistic Personality Inventory, a trait self-esteem scale, and standard measures of the three parenting dimensions. Parental warmth was associated positively and monitoring was associated negatively with both types of narcissism. Psychological control was positively associated with narcissism scores from which trait self-esteem variance had been removed. Clinical implications of the findings are discussed, limitations are addressed, and future research directions are suggested.
\end{abstract}

Robert S. Horton, Department of Psychology, Wabash College, Crawfordsville, IN. The data for Study 2 were collected while the second and third authors were undergraduate students at Wabash College. Geoff Bleau is now a psychological counselor at Supervised Lifestyles, and Brian Drwecki is a social psychology graduate student at the University of Wisconsin at Madison.

We would like to thank Dr. Beth Kurtz-Costes for her assistance in developing this project and for her helpful comments regarding earlier versions of the manuscript. We would also like to thank Dr. Jefferson Singer and two anonymous reviewers for their comments on earlier drafts of this manuscript.

Correspondence concerning this article may be addressed to the first author at P.O. Box 302, Wabash College, Crawfordsville, Indiana, 47933 or may be sent via electronic mail to hortonr@wabash.edu.

Journal of Personality 74:2, April 2006

(C) 2006, Copyright the Authors

Journal compilation (C) 2006, Blackwell Publishing, Inc.

DOI: $10.1111 / \mathrm{j} .1467-6494.2006 .00378 . \mathrm{X}$ 
Narcissism refers to a "pervasive pattern of grandiosity" that is characterized by arrogant or haughty behaviors, feelings of entitlement and superiority, and a lack of empathy for or concern about others (APA, 1994). Extremely high levels of narcissism are considered pathological, but narcissism is a normally distributed personality trait (Raskin \& Hall, 1979) that has been characterized as a system of intrapersonal and interpersonal strategies devoted to maximizing and protecting self-esteem (i.e., general feelings of self-worth; Morf \& Rhodewalt, 2001). Individuals high in narcissism (whether reaching pathological levels or not) believe that they are better than objective criteria suggest (Gabriel, Critelli, \& Ee, 1984), aggress against those responsible for ego threat (Bushman \& Baumeister, 1998) or social exclusion (Twenge \& Campbell, 2003), and experience unstable mood and self-esteem, especially in the face of failure feedback (Rhodewalt \& Morf, 1998). Indeed, social and personality psychologists have identified narcissism's personality correlates (Emmons, 1987) and interpersonal (e.g., Campbell, 1999) and intrapersonal consequences (e.g., Rhodewalt, Madrian, \& Cheney, 1998) and have now turned their attention to the developmental origins of narcissism (Ramsey, Watson, Biderman, \& Reeves, 1996; Watson, Little, \& Biderman, 1992). In this project we contribute to this new direction of narcissism research by subjecting to empirical test clinical perspectives regarding associations between narcissism and parenting behavior.

\section{Healthy and Unhealthy Narcissism?}

Narcissism is often regarded as an unhealthy characteristic, and investigations of the interpersonal functioning of narcissists support this view. In short, narcissists seem to be interpersonally inept. They make good first impressions, yet are eventually regarded negatively as arrogant and self-centered (Paulhus, 1998; Robins \& Beer, 2001). They are less committed to romantic relationships than are nonnarcissists (Campbell \& Foster, 2002) and favor (a) game-like, rather than intimate and committed, patterns of love (Campbell, Foster, \& Finkel, 2002) and (b) "trophy" romantic partners rather than those who offer the possibility of true intimacy (Campbell, 1999). Narcissism is also associated with (a) lack of empathy for others (Watson, Grisham, Trotter, \& Biderman, 1984), and (b) marked levels of hostility, especially in the face of failure feedback (Bushman, \& 
Baumeister, 1998) or social rejection (Twenge \& Campbell, 2003). Narcissism may even be related to sexual coercion, especially date rape among college students (Bushman, Bonacci, van Dijk, \& Baumeister, 2003). Of course, it is important to emphasize that narcissists' interpersonal woes may not be regrettable to the narcissist him/herself. As an example, a lack of empathy for others is not a problem for the narcissist. Indeed, reserving emotional energy for the self, rather than wasting it on others, is a perfectly logical strategy for an individual whose primary concern is the self.

In fact, recent investigations of narcissists' intrapersonal functioning have suggested that narcissism can be quite healthy (see Campbell, 2001). Narcissists tend to report high trait self-esteem (see Campbell, Reeder, Sedikides, \& Elliot, 2000), and such positive regard for the self seems to confer upon narcissists relative psychological benefit. Sedikides and colleagues (2004) found that (a) narcissism was associated with low levels of depression, anxiety, and loneliness and with high levels of subjective well-being and (b) these relations between narcissism and psychological health were completely mediated by trait self-esteem (Sedikides, Rudich, Gregg, Kumashiro, \& Rusbult, 2004).

How might we, then, understand the healthy and unhealthy aspects of narcissism? It seems that certain components of narcissism are more strongly linked to trait self-esteem, the healthful engine of narcissism, than are others. Emmons $(1984,1987)$ has identified via factor analysis four dimensions of narcissism: Leadership/Authority, Superiority/Arrogance, Self-Absorption/Self-Admiration, and Exploitativeness/Entitlement (hereafter referred to as $\mathrm{E} / \mathrm{E}$ ). The first three of these dimensions tend to be positively correlated with selfesteem (Watson, Hickman, Morris, Milliron, \& Whiting, 1995) and, consistent with the work of Sedikides and colleagues (2004), are negatively correlated with depression and anxiety (Watson \& Biderman, 1993). On the other hand, the $\mathrm{E} / \mathrm{E}$ dimension often correlates negatively, or not at all, with self-esteem and positively with depression and anxiety, especially when controlling for variance associated with the other three dimensions of narcissism (Watson \& Biderman, 1993, Watson, Little, \& Biderman, 1992). This E/E dimension is also related negatively to forgiveness and seems to reflect the more interpersonal component of narcissism (see Exline, Baumeister, Bushman, Campbell, \& Finkel, 2004), providing some explanation for narcissists' interpersonal dysfunction discussed above. In sum- 
mary, narcissism with self-esteem is relatively healthy; narcissism without self-esteem is not.

In the current article we operationalized narcissism as composite scores on the Narcissistic Personality Inventory (hereafter referred to as NPI; Raskin \& Hall, 1979; Raskin \& Terry, 1988). We operationalized unhealthy narcissism by partialling from the composite NPI scores variance associated with trait self-esteem. ${ }^{1}$

\section{The Development of Narcissism}

Empirical investigations of the origins of narcissism are scarce. Studies of personality disorders in monozygotic and dizygotic twins have suggested a genetic component of pathological narcissism (Coolidge, Thede, \& Jang, 2001; Jang, Livesley, Vernon, \& Jackson, 1996), and recent investigations have turned attention to environmental factors that may contribute to narcissism development. Most important to the current investigation, Watson and colleagues (Ramsey et al., 1996; Watson et al., 1992; Watson, Sawrie, Greene, $\&$ Arredondo, 2002) have investigated links between narcissism and parenting behavior and have been guided, as we are, by clinical psychologists' discussions of the origins of narcissistic self-regard.

\section{Clinical Perspectives on Narcissism Development}

Given the historical characterization of narcissism as a personality disorder, it is not surprising that clinical theorists have dominated the discussion about the development of narcissism. Still, clinical perspectives differ greatly in their descriptions of both the nature and the etiology of narcissism. Nearly all perspectives implicate parental behavior in some way (e.g., Imbesi, 1999; Kernberg, 1975, Kohut, 1977; Millon, 1981; Mitchell, 1988), and three historically dominant and competing perspectives blame distinct types of parenting: (a) blatantly lenient (e.g., Imbesi, 1999), (b) enmeshed and manipulative (e.g., Rothstein, 1979), or (c) unloving and strict (e.g., Kernberg,

1. For sake of simplicity, we chose to use the term narcissism to refer to the healthier form of narcissism, which is represented by composite NPI scores. When discussing the psychological consequences of composite narcissism and/or when drawing a direct contrast with unhealthy narcissism, we also use the compound term healthy narcissism to refer to these composite NPI scores. Such terminology is consistent with the work of Sedikides and colleagues (2004) discussed previously. 
1975). Before turning to a specific description of these perspectives, we review the contributions of Heinz Kohut, whose self-psychology provides an overarching theoretical perspective on the development of narcissism and for two of the three perspectives to be tested in this project.

Kohut (1977) wrote at length about the normal development of the narcissistic self and the process by which idealized images of parents and self become differentiated and realistic. According to Kohut, a child's self develops along two primary dimensions: grandiose exhibitionism and idealization. The former dimension is fostered by empathic mirroring by the parents. Parents who respond favorably to their children imbue in their children a favorable sense of self. The latter dimension, idealization, is focused first on parents who become the child's role model for standards of behavior, which, upon successful development, will be internalized by the child. Successful development of the two dimensions of the self is facilitated by "optimal frustrations" of the child by a parent. The "frustrations" are specific instances in which a child is left without parental support or guidance and is forced to rely upon his or her own faculties. Such "optimal frustrations" are thought to moderate the child's sense of grandiosity to realistic levels and to aid the internalization of the sense of ideal from the parent. In the face of parenting that is either (a) so lenient that there is no frustration of the grandiose self or (b) so controlling as to retard independence, unhealthy narcissistic qualities may develop.

The former of these sentiments leads to the first of the three primary perspectives on the development of narcissism: narcissism may result from parental overindulgence and permissiveness. Kohut provides a psychodynamic perspective that predicts this outcome, and Millon and colleagues counter with a social learning perspective that converges upon the same prediction (Millon \& Everly, 1985). According to the social learning perspective, indulgent and permissive parenting leads to narcissism not because of a failure to separate intrapsychically from infantile fantasies of self or of parent but because such parenting teaches the child that he or she is superior, that he or she is entitled to special treatment regardless of effort, behavior, or performance. Feelings of grandiosity and entitlement, which are characteristic of the narcissistic self, are learned, and even mimicked, from parental behavior toward the child. Kohut's and Millon's perspectives converge upon a prediction but differ in the 
underlying mechanism that guides the predicted associations. In this project we focus on these predicted associations and leave theoretical interpretation and differentiation to future work and discussion.

Kohut's work also provides insight into the second of the three competing predictions about how narcissism may be related to parenting. Kohut's idea of parental enmeshment (i.e., overcontrol that subverts the independent self) converges with object relations theorists (e.g., Rothstein, 1979) to suggest that childhood narcissism is a response to the parent's narcissistic use of the child. As noted above, a parent who does not provide the optimal failures that children need in order to break away psychologically from the parent can foster a narcissistic child who is constantly dependent upon external sources of guidance and feedback. Object relations theorists offer a related perspective and infer a motive underlying the parent's behavior. According to this perspective, narcissism develops when the parent regards the child as a means by which to satisfy selfish motives, not as an individual to be nurtured. In this unfortunate case, the parent's identity is enmeshed with the child's, and the parent subverts the development of the child's independent sense of self rather than risk a symbolic loss to his or her own self. In this case, the child's narcissistic self is a manifestation of an ongoing and desperate search for approval from the idealized object (initially the parent and eventually transferred to other important individuals). Indeed, Rothstein argues that narcissism is at its core a result of a parent selfishly undermining the child's development of an independent sense of self: the narcissist's parent is one who is overly involved with the child and thus does not allow the child to break from the parent and establish personal standards of success. Kohut's selfpsychology and object relations theorists differ in their description of the mechanism but converge on the prediction that narcissism will be associated with parents who are characterized by overinvolved enmeshment with their child.

The final perspective on narcissism development is offered by Otto Kernberg (1975), who suggests that narcissism develops as a result of pathological organization of the self (one's beliefs about the self), ideal self (an idealized image of the self), and ideal object (an idealized image of another individual, usually a parent; for a review see Kernberg, 1975). Kernberg suggests that this pathological organization is a consequence of parents who are cold and harsh toward a child but who also regard the child as gifted or special. To 
quote Kernberg, narcissistic children "often occupy a pivotal point in their family structure, such as being the only child, or the only 'brilliant' child, or the one who is supposed to fulfill family aspirations" (Kernberg, 1975, p. 235). In many cases of narcissism, parents have used the child for vicarious fulfillment of their own failed ambitions, a sentiment that rings of the object relations view described above but which is contrasted by a marked lack of parental support for the child. Put simply, Kernberg's perspective suggests that the combination of parental coldness, extremely high expectations, and harsh demands leads to the child's narcissistic self.

Clearly, there is substantial disagreement about what kind of parenting is associated with narcissism. The primary goal of this project was to examine relative support for each of these perspectives. The parenting literature provided empirical description and validation of parenting dimensions, by which we operationalized the clinical perspectives on narcissism.

\section{Parenting}

The empirical work on parenting has identified a variety of parenting dimensions that influence childhood functioning. These dimensions include, but are not limited to, restrictiveness (Baldwin, 1955; Baumrind \& Black, 1967), demandingness (Roe \& Siegelman, 1963), overprotection (Parker, Tupling, \& Brown, 1979), involvement, strictness and supervision (Baumrind, 1967, 1971), and psychological control (Barber, Olsen, \& Shagle, 1994; Schaeffer, 1965). Many recent investigations have operationalized parenting as styles (e.g., Baumrind, 1971; Lamborn, Mounts, Steinberg, \& Dornbusch, 1991; Maccoby \& Martin, 1983), which are typical strategies of parenting that combine unique combinations of the parenting dimensions described above. In this article we do not limit our investigation to parenting styles but focus on the sole and interactive influences of parental warmth, monitoring, and psychological control, three components that summarize the variety of parenting terms and that are often combined in unique ways to form parenting styles (see Baumrind, 1991a; Cumming, Davies, \& Campbell, 2000; Grolnick, 2003).

\section{Warmth}

Parental warmth has been investigated under numerous names, including involvement, acceptance, child-centeredness, and responsive- 
ness. Each of these terms refers to the extent to which parents "provide emotional and material resources" for their child (Grolnick, 2003, p. 2). In this project we follow the lead of Steinberg and colleagues (see Steinberg, Elman, \& Mounts, 1989; Steinberg, Lamborn, Darling, Mounts, \& Dornbusch, 1994) in operationalizing parental warmth as parental acceptance and involvement with their child.

In general, the impact of parental warmth on child functioning is favorable. Children who have accepting, loving, and involved parents tend to have higher self-esteem (Coopersmith, 1967; Loeb, Horst, \& Horton, 1980) and greater sociability (Clarke-Stewart, 1973; Rothbaum, 1988), display better self-regulation (Stayton, Hogan, \& Ainsworth, 1971), and achieve more success in school (Steinberg, Elmen, \& Mounts, 1989) than those who do not. Of course, the influence of warmth on child functioning depends upon the variable of interest (e.g., warmth has less to do with behavioral delinquency and more to do with self-esteem), the manner in which warmth is combined with other parenting practices (e.g., whether a warm parent encourages autonomy; Weiss \& Grolnick, 1991 as cited in Grolnick, 2003), and the particular type of warmth one is studying (e.g., caring vs. involvement; Pettit, Bates, \& Dodge, 1997). We investigated both the sole influence of warmth on narcissism as well as the manner in which warmth could moderate, or be moderated by, the impact of other parenting dimensions.

\section{Monitoring}

Monitoring refers to a parent's attempts to keep track of where a child is and what he or she is doing, and it is a fundamental component of a parent's attempts to establish and enforce rules (i.e., behavioral control; Cumming et al., 2000). Monitoring is linked concurrently and prospectively to decreased externalized characteristics, including delinquency, drug use, truancy, and fighting (Barber et al., 1994; Herman, Dornbusch, Herron, \& Herting, 1997), even when one controls for other aspects of behavioral control (e.g., consistent discipline; Patterson \& Stouthamer-Loeber, 1984), Monitoring also predicts positive academic outcomes in adolescents when controlling for other parenting dimensions, like parental warmth (Steinberg et al., 1994).

For the current project, it is interesting to note that monitoring is not often associated independently with internalized characteristics 
(i.e., self-esteem and depression; Barber, 1996), which would seem to undermine its usefulness in an investigation of narcissism. However, as we will discuss in more detail below, the theoretical perspectives on narcissism development implicate monitoring in combination with other parenting dimensions.

\section{Psychological Control}

Early discussions of parenting (Becker, 1964; Schaefer, 1965), including the original "parenting styles" typology (Baumrind, 1991a), considered psychological control a critical parenting dimension. Psychological control refers to "control attempts that intrude into the psychological and emotional development of the child" (Barber, 1996, p. 3296) and includes, among other things, manipulation of a child via guilt induction or withdrawal of love, personal control of a child (via possessiveness), and expressions of disappointment and shame in a child. Psychological control has been distinguished empirically from monitoring (e.g., Barber et al., 1994; Steinberg, 1990) and is regarded as a particularly insidious parental tactic that undermines a child's autonomous development (Baumrind, 1991b). Whereas monitoring (as mentioned above) predicts, primarily, externalized characteristics (e.g., delinquent behavior), high levels of psychological control are most often associated with internalized, self-concept-related characteristics. For example, children who describe their parents as psychologically controlling also report relatively high levels of depression and low levels of self-esteem (Barber, 1996; Barber, et al., 1994). Further, the effects of psychological control on adolescent somatic symptoms persist when controlling for warmth and monitoring (Herman et al., 1997). In the current study we investigate the direct influence of psychological control and its interactive influence with monitoring and warmth. Such interactive influence has yet to be investigated empirically.

\section{Previous Work on Narcissism and Parenting}

Watson and colleagues have devoted significant empirical energy to investigations of parenting and narcissism (Watson et al., 1992). These researchers have been guided, primarily, by Kohut's self psychology and have operationalized parenting with the Parental Authority Questionnaire (Buri, 1991), which approximates Baumrind's authoritative, authoritarian, and permissive parenting styles (Baum- 
rind, 1971). Their work suggests that (a) permissive and authoritative parenting are associated with the $\mathrm{E} / \mathrm{E}$ dimension of narcissism (associated positively and negatively, respectively; Watson et al., 1992) and (b) both permissive and authoritarian parenting are positively associated with an assessment of pathological narcissism (O'Brien Multiphasic Narcissism Inventory; O'Brien, 1987).

We extend the work of Watson and colleagues in a number of ways. First, we have expanded our theoretical base beyond the work of Kohut to other psychodynamic, social learning, and object relations theorists. Second, instead of using a parenting typology, we assess parenting dimensions (i.e., warmth, monitoring, and psychological control) that are the foundations of different parenting typologies (e.g., Baumrind, 1991; Maccoby \& Martin, 1983). Such a tactic will allow us to (a) identify both the parenting styles and the specific aspects of parenting that are proximally linked to narcissism and (b) investigate the associations between narcissism and those unique combinations of parenting components that do not fit neatly into a parenting style.

\section{Hypotheses}

The literature reviewed above guided a set of three competing hypotheses (See Table 1 for hypotheses). Millon's social learning theory and Kohut's ideas of parental leniency suggest that narcissistic children will report that their parents are loving and involved but are not strict (what others have called "permissive" parents; Baumrind, 1991a, Maccoby \& Martin, 1983). This perspective would receive support in either of two statistical situations: (a) the main effects of warmth and monitoring predict narcissism positively and negatively, respectively, thus suggesting a combinatory effect by which parents who are reported to be high in warmth but low in monitoring have children with the highest narcissism scores or (b) warmth and monitoring interact to predict narcissism such that children who report high parental warmth but low parental monitoring manifest the highest narcissism scores.

Kohut's emphasis on parental enmeshment converges with object relations theorists to predict that narcissism results from overinvolved parents who fail to nurture an autonomous self. Thus, parents who are reported to be psychologically controlling and also involved with their children should have children who are the most narcissistic. This perspective would receive statistical sup- 
Table 1

Hypotheses Derived From Clinical Perspectives on Narcissism

Development

Theoretical Perspective(s)

Hypothesis

1) Kohut's parental leniency

Narcissism will be positively associated with

2) Millon's social learning parental warmth and negatively associated with parental monitoring (suggesting permissive parents).

1) Kohut's enmeshment

Narcissism will be positively associated with

2) Object relations psychological control and positively associated with warmth.

1) Kernberg's psychodynamic Narcissism will be negatively associated with parental warmth and positively associated with monitoring and psychological control.

Note. Each perspective predicts main effect associations between the specific dimension and narcissism; however, each perspective may also be supported by a particular interactive association (discussed in the text).

port if both the main effect associations between psychological control and narcissism and between warmth and narcissism were positive. The perspective would also receive support if psychological control and warmth interacted such that the highest narcissism scores were associated with high levels of warmth and psychological control.

Finally, Kernberg's perspective suggests that narcissistic children will have parents who are cold but strict and controlling. This combination of parenting dimensions has been labeled "authoritarian" by other theorists (e.g., Maccoby \& Martin, 1983). Kernberg's perspective would receive support if the main effect of warmth is associated negatively with narcissism, but the main effects of monitoring and psychological control are associated positively. The perspective would also receive support from an interaction among the parenting dimensions such that participants who report low warmth, high monitoring, and high psychological control report the highest narcissism scores.

We tested these hypotheses by soliciting from college and high school students self-reports of narcissism, self-esteem, and parenting (i.e., reports of their parents' warmth, monitoring, and psychological 
control). We investigated main effect and interactive associations of parenting components with (a) narcissism (i.e., the composite NPI score) and (b) unhealthy narcissism (i.e., NPI scores after partialling out variance associated with trait self-esteem).

It is important to note that we maintained the same set of competing hypotheses for both outcome measures (i.e., narcissism and unhealthy narcissism). The perspectives that drove our hypotheses do not distinguish clearly between the healthy and unhealthy components of narcissism when theorizing about links with parenting behavior.

\section{STUDY 1: COLLEGE STUDENTS}

In Study 1 college students completed assessments of narcissism, trait self-esteem, and parenting dimensions. Participants reported retrospectively about how they were parented; none of the participants lived with their parents at the time of assessment.

\section{Method}

\section{Participants}

Two hundred and twenty-two introductory psychology students (139 women and 62 men, 21 participants did not report gender) at the University of North Carolina at Chapel Hill participated as partial fulfillment of a course option. The mean age of the participants was 19.00 years $(S D=1.02$; range $=17-22)$. The sample was predominantly Caucasian (estimate of $80 \%$ ) and was composed of 71 freshman, 112 sophomores, 13 juniors, and 7 seniors (19 participants did not report academic year). ${ }^{2} \mathrm{We}$ did not collect data regarding the participants' parental backgrounds (i.e., whether parents were married, living together, separated, or divorced).

\section{Materials}

Warmth and monitoring (Lamborn et al., 1991). The items assessing warmth and monitoring were taken from the parenting styles measure developed by Lamborn and colleagues to approximate the four-style classification of parenting proposed by Maccoby and Martin (1983).

2. In order to guard against inaccurate memories of parental behavior during adolescence, the data from two participants, ages 28 and 37, were discarded. 
The warmth assessment included 15 items that assessed parents' encouragement of (e.g., "She keeps pushing me to do my best in whatever I do."), support of (e.g., "I can count on her to help me out if I have some kind of problem.") and involvement with (e.g., "My parents spend time just talking with me.") the respondent. Five items assessed warmth of the male guardian, and five items assessed warmth of the female guardian. Participants responded to these 10 items by indicating "how true" each statement was $(1=$ always false, and $4=$ always true $)$. Five additional items referred, generally, to "parents/guardians" and included endpoints unique to the item (e.g., "My family does something fun together" answered on a scale ranging from Almost every day to Almost never).

In line with common practice, we created a composite warmth index (with a possible range 10-40) by (a) summing the five items referring to the female guardian (female composite; alpha $=.70$ ) and the five items referring to the male guardian (male composite; alpha $=.78$ ), (b) averaging the male and female composites (to create a parental composite), and (c) summing the parental composite and the five "parents/guardians" items (alpha $=.65)$. Higher scores indicate more parental warmth. Participants who were raised by only one guardian did not complete items about the other guardian.

The monitoring assessment included nine items that assessed (a) how much participants' parents actually knew and how much they tried to know about the child's social activities and relations (e.g., "How much do your parents REALLY know about where you go at night? answered on a scale ranging from Don't know to Know a lot) and (b) curfew times for weekdays and weekends. We created a composite index by standardizing each item (to account for differences in scaling) and then summing the nine standardized items $($ alpha $=.78)$. Higher scores indicate higher levels of parental monitoring.

Psychological control scale. We assessed psychological control with the 10-item psychological control subscale from the revised Children's Report of Parental Behavior Inventory (CRPBI; Barber, 1996; Schaefer, 1965). Participants completed the scale separately for male and female guardians. The scale assesses participants' perceptions of their parents' (or guardians') use of various components of psychological control such as guilt induction, love withdrawal, and excessive pressure to change (e.g., "My father is a person who is less friendly with me if I do not see things his way" answered on a 3-point scale: $1=$ Not like him to $3=A$ lot like him). Consistent with recent investigations of psychological control (Barber, 1996; Soucy \& Larose, 2000), we included only 6 of the 10 items in the composite index of psychological control. The four excluded items have been deemed ambiguous regarding the extent to which they differentiate 
between psychological control and monitoring (see Barber, 1996). We created the composite index for psychological control (with a possible range 6-18) by (a) summing the six items assessing psychological control by the female guardian (female control; alpha $=.76$ ) and summing the six items assessing psychological control by the male guardian (male control; alpha $=.81)$ and $(b)$ averaging the male and female guardian composites. Higher scores indicate higher levels of psychological control. Participants who were raised by only one guardian completed items only about that guardian.

Narcissistic Personality Inventory (NPI; Raskin \& Hall, 1979). The NPI is a 40-item measure that assesses narcissism as a normally distributed personality trait (Raskin \& Hall, 1979). The scale exhibits satisfactory internal consistency (in validation sample, alpha $=.81$; in current sample, alpha $=.88)$. The original scale yielded one component score for narcissism and seven first-order component scores (Authority, Self-Sufficiency, Superiority, Entitlement, Exhibitionism, Exploitativeness, and Vanity); however, Emmons $(1984,1987)$ identified only four dimensions (Leadership/Authority; Superiority/Arrogance; Self-absorption/Self-admiration; Exploitativeness/Entitlement) in the original 54-item scale (Raskin \& Hall, 1979). ${ }^{3}$

The NPI has been used widely and shows satisfactory convergent and discriminant validity (Bushman \& Baumeister, 1998; Emmons, 1987; Morf \& Rhodewalt, 1993; Rhodewalt, et al., 1998; Rhodewalt \& Morf, 1998). For each of the 40 scale items, respondents must choose with which of two statements they most agree. As an example, consider Item 13. Respondents must choose between option A ("I find it easy to manipulate people.") and option B ("I don't like it when I find myself manipulating people."). For each item, one choice is considered "narcissistic," and one choice is considered "non-narcissistic." We created a composite score of narcissism (with a possible range 0-40) by counting the number of "nar-

3. The reader may wonder why we did not assess associations between parenting components and each of these subscales, especially the $\mathrm{E} / \mathrm{E}$ dimension (which is primarily associated with interpersonal dysfunction). The primary explanation for this decision lies in the relative unreliability of the subscale scores. We computed composite scores from the NPI that were consistent with Emmons's dimensions, which he derived by factor-analyzing a 54-item version of the NPI. Only one of the four dimensions displayed adequate internal consistency. We further reasoned that the unhealthy components of narcissism likely include more than just the $\mathrm{E} / \mathrm{E}$ dimension and would be captured effectively by a narcissism score from which trait self-esteem had been partialled out. 
cissistic" responses endorsed by each participant. Higher scores indicate higher levels of narcissism.

\section{Rosenberg's Self-Esteem Scale (RSE; Rosenberg, 1986)}

The 10 items of the RSE assess global feelings of self-worth (e.g., "I am able to do things as well as most other people"). Respondents indicate their agreement with each item on a scale ranging from 1 (strongly disagree) to 4 (strongly agree). We created a composite self-esteem score (with a range of $10-40$ ) by summing the ten items (alpha $=.87$ ). Higher scores indicate higher self-esteem.

\section{Procedure}

Participants completed the NPI, the parenting styles assessment, the psychological control scale, and the RSE individually. Presentation order of the scales was randomized. Because specific items in the parenting styles assessment addressed issues that were not necessarily relevant to college students (e.g., curfew on weekdays and weekends), participants completed this assessment about their senior year of high school.

\section{Results}

\section{Descriptives and Bivariate Correlations}

Narcissism $(M=17.26, S D=7.69)$ and self-esteem $(M=33.92$, $S D=4.55$ ) scores were comparable to previous investigations (see Campbell et al., 2000; Heatherton \& Polivy, 1991). Males and females reported similar levels of narcissism $(M=17.94, S D=7.52$; $M=16.95, S D=7.77$, respectively), $t(215)=.89, p<.40$, and selfesteem $(M=34.24, S D=4.38 ; M=33.78, S D=4.65$, respectively $)$, $t(215)=.69, p<.50$.

Reports of the three parenting components were significantly related to one another. Warmth was correlated positively with monitoring, $r(222)=.35, p<.001$, but negatively with psychological control, $r(222)=-.42, p<.001$. The more involved and caring participants reported their parents to be, the higher the monitoring but the lower the psychological control they tended to report. Monitoring and psychological control were also correlated negatively, $r(222)=-.15, p=.02$. The more monitoring the participants reported, the less psychological control they tended to report. 


\section{Principal Analysis Strategy}

We used multiple regression analysis to assess hypotheses regarding the links between parenting and (a) narcissism and (b) unhealthy narcissism. First, we regressed composite narcissism scores onto warmth, monitoring, psychological control, and interactions among the parenting components. As discussed above, this analysis reflects an investigation of healthy narcissism. We also investigated parenting associations with unhealthy narcissism. To partial from narcissism scores the variance associated with trait self-esteem, we regressed narcissism onto self-esteem and saved the residual narcissism score. We then regressed this partialled narcissism score onto warmth, monitoring, psychological control, and interactions among the three parenting components. We standardized all predictors and outcome measures. ${ }^{4}$

Degrees of freedom vary slightly for each analysis. Discrepancies were caused by participants who either did not complete all experimental measures or who completed measures incorrectly.

\section{Narcissism}

The overall model predicting narcissism from parenting components and interactions among parenting components was significant, $F$ (7, $214)=2.47, p=.02 ; R^{2}=.08$, and parental warmth, $\beta=.29, t(214)$ $=3.71, p<.001, \eta^{2}=.06$, was the only significant predictor of narcissism. The more parental warmth the participants reported, the higher the levels of narcissism they reported. No other main effects and no interactions among parenting components reached even marginal levels of significance (all $p \mathrm{~s}>.18$, all $\eta^{2} \mathrm{~s}<.01$ ).

\section{Unhealthy Narcissism}

When we regressed the unhealthy narcissism scores onto the parenting components and their interactions, a slightly different picture emerged. Parental warmth predicted unhealthy narcissism positively and significantly, $\beta=.17, t(214)=2.37, p=.02, \eta^{2}=.03$, and so did

4. In an initial regression analysis, we included participant sex as a predictor of narcissism and self-esteem. Participant sex did not interact with any of the parenting dimensions to predict narcissism or unhealthy narcissism. These null results involving participant sex are available from the first author. 
psychological control, $\beta=.18, t(214)=2.55, p=.01, \eta^{2}=.03$. The more parental warmth and psychological control that participants reported, the higher their unhealthy narcissism scores tended to be. The monitoring main effect and the interactions between and among the parenting components did not reach even marginal levels of significance (all $p s>.28$, all $\eta^{2} \mathrm{~s}<.01$ ).

\section{Discussion}

Study 1 provided a preliminary investigation of the associations among parenting dimensions, narcissism, and trait self-esteem and revealed that college students' ratings of their parents' warmth were associated positively with their scores on both healthy and unhealthy narcissism. Reports of psychological control were also associated positively with unhealthy narcissism. These data suggest, albeit tentatively, that Kohut's and the object relations theorists' indictment of overinvolved, controlling parents may have merit, at least for the unhealthy components of narcissism.

Study 1, however, is fraught with a variety of methodological challenges that temper our confidence in conclusions drawn solely from these data. Most critically, all participants were college students who did not live with their parents and thus were not under the immediate influence of the parenting about which they were reporting. Participants were asked to recall how their parents treated them during their senior year of high school, a procedure that may lend itself to memorial biases and inconsistencies. Study 2 remedied this problem.

\section{STUDY 2: HIGH SCHOOL STUDENTS}

In Study 2 we sampled high school students who were living with their guardians at the time of testing. As in Study 1, students completed measures of narcissism, self-esteem, and parenting dimensions.

\section{Method}

\section{Participants}

Participants were 214 high school students from either Crawfordsville, Indiana, or Bay City, Michigan. With the support of the principals of three different high schools, we recruited 127 women and 87 men by 
distributing fliers at high schools in both towns. The sample was predominantly Caucasian $(>90 \%)$, ranged in age from 13 to 18 years $(M=15.42, S D=1.10)$, and included all four high school grade levels (33\% freshman, $27 \%$ sophomores, $23 \%$ juniors, and $17 \%$ seniors). We did not collect data regarding the sample participants' parental backgrounds. In exchange for participation, participants were given a $\$ 5$ Blockbuster coupon and were entered into a lottery for more valuable prizes (e.g., DVD players and TV sets).

\section{Measures}

Participants completed the same narcissism, self-esteem, and parenting assessments that were described in Study 1. The internal consistency for each assessment was adequate (Cronbach's alphas: NPI $=.82$; Rosenberg's self-esteem $=.84$; parental warmth $=.74$, mother warmth $=.78$, father warmth $=.86$; monitoring $=.70$; mother psychological control $=.73$, father psychological control $=.85$ ). We created composite indices for narcissism, self-esteem, parental warmth, monitoring, and psychological control in the same manner as described in Study 1. Higher scores on each measure indicated more of the construct.

\section{Procedure}

Participants completed the NPI, the parenting styles assessment, the psychological control scale, the RSE, and several other assessments (that were unrelated to this project) in small groups $(n=2-10)$. Measures relevant to this project were always completed first, but the order of these measures was randomized. After completing the questionnaire, participants were thoroughly debriefed and were given their compensation.

\section{Results}

\section{Descriptives}

Narcissism $(M=17.78, S D=6.88)$ and self-esteem $(M=30.76, S D=$ 5.39) scores were comparable to those in Study 1. Males reported higher levels of narcissism $(M=19.03, S D=6.44$ vs. $M=16.98$, $S D=7.05), \quad t(196)=2.05, \quad p<.05, \quad$ and self-esteem $\quad(M=32.01$, $S D=4.99$ vs. $M=29.90, S D=5.51), t(211)=2.86, p<.05$, than did females. As expected, narcissism and self-esteem were correlated positively (Table 2).

Parenting components were correlated significantly with one another, and the pattern of correlations replicated Study 1. Warmth 
Parenting and Narcissism

\section{Table 2}

Study 2 Bivariate Correlations Among Self-Esteem, Narcissism, and Parenting Components

\begin{tabular}{lcccc}
\hline & 1 & 2 & 3 & 4 \\
\hline 1. Self-Esteem & & & & \\
2. Narcissism & $.34^{* * *}$ & & & \\
3. Warmth & $.36^{* * *}$ & .02 & & \\
4. Monitoring & $.24^{* *}$ & $-.18^{* * *}$ & $.45^{* *}$ & \\
5. Psychological Control & $-.26^{* *}$ & .10 & $-.44^{* *}$ & $-.24 * *$ \\
$* * p<.01$. & & & &
\end{tabular}

was correlated positively with monitoring but negatively with psychological control. Psychological control was also correlated negatively with monitoring (Table 2).

\section{Principal Analysis Strategy}

We standardized all predictors and outcomes in order to correct for scale differences and followed the same series of analyses as discussed for Study 1. We investigated narcissism and unhealthy narcissism as a function of the sole and interactive influence of parenting components.

\section{Narcissism}

The overall model predicting narcissism from parenting components and interactions among parenting components was significant, $F$ $(7,172)=2.44, p=.02 ; R^{2}=.09$. As in Study 1, reports of parental warmth were positively and significantly associated with narcissism scores, $\beta=.25, t(172)=2.75, p=.007, \eta^{2}=.04$; the higher the level of parental warmth reported, the higher the narcissism score. In addition, monitoring scores were negatively related to narcissism, $\beta=-.29, t(172)=-3.19, p=.002, \eta^{2}=.05$; the less monitoring the participant reported, the higher the participant's narcissism score tended to be. It is also worth noting that psychological control scores were associated positively, though not significantly, with narcissism scores, $\beta=.14, t(172)=1.60, p=.11, \eta^{2}=.01$. 
In addition to the main effects described above, the monitoring $\times$ psychological control interaction also reached significance, $\beta=.18$, $t(172)=2.06, p=.04, \eta^{2}=.02$. Inspection of the simple slopes for psychological control at high and low levels of monitoring (one standard deviation above and below the mean for monitoring) indicates that reports of psychological control were positively associated with narcissism at high levels of monitoring, $\beta=.15, p=.14$, but were negatively and weakly associated with narcissism at low levels of monitoring, $\beta=-.05, p=.67$. Predicted narcissism values for hypothetical participants one standard deviation above and below the means of psychological control and monitoring suggest, further, that the interaction was driven largely by the low narcissism scores of those participants who reported high levels of monitoring and low levels of psychological control.

There were also no other significant interactions between parenting components. It is also worth noting here that participant sex did not interact significantly with any of the parenting variables.

\section{Unhealthy Narcissism}

Within the entire sample of participants, the overall model predicting unhealthy narcissism scores from parenting components and interactions among parenting components was significant, $F(7,172)=$ $4.27, p<.001 ; R^{2}=.15$. Consistent with Study 1 and with the analyses of narcissism reported above, warmth predicted unhealthy narcissism positively and significantly, $\beta=.17, t(172)=1.99, p=.048$, $\eta^{2}=.02$. Both psychological control, $\beta=.18, t(172)=2.27, p=.02$, $\eta^{2}=.03$, and monitoring, $\beta=-.32, t(172)=-3.85, p<.001$, $\eta^{2}=.07$, also predicted unhealthy narcissism significantly. The higher the levels of psychological control and the lower the levels of monitoring, the higher the participants' unhealthy narcissism scores tended to be. Monitoring and psychological control also interacted to predict unhealthy narcissism, $\beta=.18, t(172)=2.29, p=.02 .^{5}$

While these full sample data replicate and extend the findings of Study 1, they do not tell the full empirical story; participant sex also interacted with parenting dimensions to predict unhealthy narcissism. More specifically, sex interacted significantly with psycholog-

5. This interaction reached significance only for female participants and thus, is interpreted below. 
ical control, $\beta=-.18, t(166)=-2.14, p=.03$, and with warmth and psychological control (creating a three-way interaction), $\beta=.18$, $t(166)=4.84, p=.02$. In order to explore these interactions in more detail, we analyzed data for men and women separately.

Analysis on men. For men, monitoring was the only significant predictor of unhealthy narcissism, $\beta=-.33, t(63)=-2.54$, $p=.01, \eta^{2}=.09$. No other main effects or interactions approached significance (all $p s>.46$, all $\eta^{2} s<.01$ ).

Analysis on women. For women, psychological control, $\beta=.32, t$ $(101)=3.34, p<.01, \eta^{2}=.08$, and warmth, $\beta=.18, t(101)=1.74$, $p=.08, \eta^{2}=.02$, predicted unhealthy narcissism positively, albeit marginally for warmth. Monitoring predicted unhealthy narcissism negatively, $\beta=-.25, t(101)=-2.29, p=.02, \eta^{2}=.04$. In addition, psychological control interacted significantly with warmth, $\beta=-.23, t(101)=-2.48, p=.02$, and with monitoring, $\beta=.22$, $t(101)=2.35, p=.02$.

Simple slopes and predicted values (See Figure 1) for the warmth $\times$ psychological control interaction suggest that (a) psychological control was positively associated with unhealthy narcissism under both high and low warmth conditions (simple slopes for psychological control: $\beta=.22, p=.06$ and $\beta=.44, p=.001$ at $1 S D$ above and below the warmth mean, respectively), but (b) the association between unhealthy narcissism and psychological control was

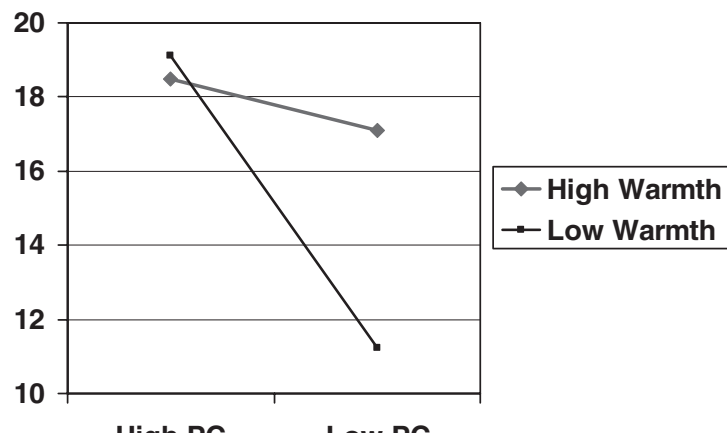

High PC Low PC

Figure 1

Predicted NPI values for hypothetical females 1 SD above and below the means of warmth and psychological control. 


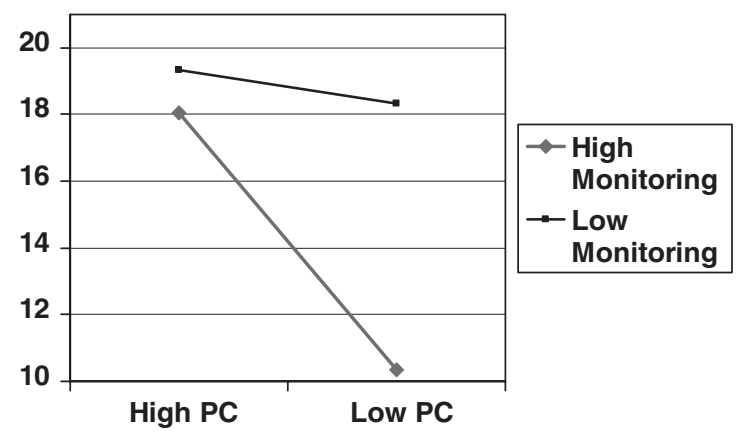

Figure 2

Predicted NPI values for hypothetical females $1 S D$ above and below the means of monitoring and psychological control.

particularly potent under conditions of low warmth, with participants who report low warmth and low psychological control reporting the least unhealthy narcissism.

Simple slopes and predicted values (See Figure 2) for the monitoring $\times$ psychological control interaction suggest that reports of high psychological control are consistently associated with higher levels of unhealthy narcissism (simple slopes for psychological control: $\beta=.40, p=.001$ and $\beta=.11, p=.31$ at $1 S D$ above and below the monitoring mean, respectively). However, this association is particularly powerful at high levels of monitoring. Indeed, females who reported high levels of monitoring and low levels of psychological control reported the lowest unhealthy narcissism scores.

\section{Discussion}

In Study 2 we investigated further the predictive power of parenting dimensions on narcissism and unhealthy narcissism. The high school participants of Study 2 were under the immediate guidance of their parents, and the findings provide partial replication of and interesting extension to those of Study 1.

Like Study 1, parental warmth was positively associated with healthy and unhealthy narcissism, and psychological control was associated positively and significantly with unhealthy narcissism. Unlike in Study 1, monitoring scores predicted both healthy and unhealthy narcissism scores negatively. The less monitoring that the participants reported from their parents, the higher the narcissism 
scores tended to be. These data are consistent with Millon's and Kohut's prediction that narcissism results from parental overindulgence and unbridled affection for a child. Additionally, the finding that both warmth and psychological control predicted unhealthy narcissism positively lends support to the notion that parents whose involvement is colored by attempts at guilt induction and love withdrawal promote narcissistic self-regard by undermining the independent development of the child's self (the Kohut/object relations view).

Study 2 also revealed interesting sex differences on associations of parenting with unhealthy narcissism. The association of monitoring with unhealthy narcissism was consistent across sex; however, for males, unhealthy narcissism was not associated with parental warmth or with psychological control, as it was for females. Further, the analysis on only women revealed two interesting interactions between parenting components. Though we hesitate here from conjecturing too strongly about the specific implications of the female interactions, it is interesting to consider the possible interpretations of the presence of these sex differences. The data could suggest that females are more sensitive to the nuances of parenting than are males, as evidenced by the complexity of the associations between their personality scores and their reports of parenting. Our self-report methodology precludes substantial confidence in this interpretation, yet it is a possibility that lends itself to further exploration.

The limitations of this methodology and the implications of our principal findings for understanding narcissism development are discussed below.

\section{GENERAL DISCUSSION}

In two studies we investigated the direct and interactive associations of parental warmth, monitoring, and psychological control with narcissism and unhealthy narcissism. Unlike other investigations of parenting and child outcomes, we did not limit our analyses to a parenting typology, opting instead to allow unique combinations of main and interactive effects to emerge as we investigated the predictive power of the parenting components on healthy narcissism (which includes trait self-esteem) and its unhealthy companion (narcissism after removing variance associated with self-esteem). The two 
studies differed somewhat in their results and thus in their implications for the clinical perspectives under consideration. We discuss these findings below with a particular focus on Study 2, which included high school students who lived at home under the immediate guidance of their parent(s).

The data suggest that indulgent, permissive parenting is linked to healthy narcissism, a result that is consistent with both Millon's social learning perspective and Kohut's discussion of parental leniency. In both studies, parental warmth was positively associated with healthy narcissism, and importantly, Study 2 revealed the predicted pattern of narcissism's positive association with warmth and negative association with monitoring. Indeed, the data suggest that parents who lavish affection upon their children without setting boundaries for them may enable a narcissistic self to develop. We leave open the question of whether this result is due to social learning (as proposed by Millon) or to an early childhood experience in which parents fail to inculcate frustration that can rein in the favorable selfregard that results from positive mirroring (Kohut's perspective). Of course, given that (a) the current data were obtained from high school and college-age students and (b) Kohut's perspective emphasizes early childhood experiences, the results seem to favor Millon's approach. It is also important to remember that the narcissism with which this indulgence is linked and which includes trait self-esteem has been associated with positive psychological health (Sedikides et al., 2004). Thus, parental indulgence may be associated with ultimate psychological benefit.

On the other hand, reports of involved but lenient parenting were also associated in Study 2 with unhealthy narcissism (though monitoring did not predict unhealthy narcissism in Study 1). The key to understanding the associations of permissive parenting with both narcissism and unhealthy narcissism may lie in psychological control. Indeed, psychological control was the only one of the parenting dimensions to predict unhealthy narcissism scores without also predicting composite, healthy narcissism. This result may suggest that, consistent with the ideas espoused by Kohut and object relations theorists, psychological control tactics, like guilt induction and love withdrawal, may contaminate the potentially positive autonomyfostering influences of the other parenting dimensions.

These psychological control tactics may provide an insidious context in which parents' involvement with the child and even their lack 
of monitoring of the child are interpreted (see Grolnick, 2003). For instance, a child may be made to feel ashamed or unloved if he or she does not meet parental academic expectations, and the child may infer that the parents remain involved with and supportive of the child only on the condition that the child meet or exceed the parents' expectations. Over time, psychological control tactics may create a sense of contingency between one's behavior (and thoughts) and the parents' affection and disciplinary strategies. A child who learns, and is continuously reminded, that his or her worth in the eyes of parents is determined by the extent to which his or behavior matches with the parents' expectations, rather than with his or her own, may develop a chronic dependence upon external sources for assessment and bolstering of the self. As Kohut would argue, such parenting impairs the transition of standards from external sources to internal ones that is a hallmark of healthy self-development. In contrast, standards remain external to the self, and the narcissistic self is left to continuously seek and monitor external validation of behavior.

It is interesting to note that such an external contingency is consistent with much of what we know about narcissists' interpersonal behavior. For example, if one is particularly concerned about feedback from others, it is wise to choose, as narcissists do, romantic partners who are externally, rather than internally, appealing (Campbell, 1999). Further, it makes sense that negative feedback from others would lead to intense emotional and aggressive responses (e.g., Twenge \& Campbell, 2003). After all, such feedback would be particularly hurtful to the self since the external feedback is chronically salient and there is no internal positive buffer from its impact. Our findings are also consistent with (a) the recent suggestion that narcissism includes a particular type of fragile self-esteem (see Kernis, 2001) and (b) the finding that such fragile self-esteem is linked with a contingent sense of self-worth (Crocker, Karpinksi, Quinn, \& Chase, 2003).

We should also acknowledge here that in Study 2 the statistical support for the Kohutian/object relations view was isolated to female participants. For male participants, only monitoring predicted unhealthy narcissism scores in that lower levels of monitoring were linked to higher levels of unhealthy narcissism. In contrast, females showed complex patterns of relationship among warmth, psychological control, and monitoring that predicted unhealthy narcissism. 
One possible explanation for this sex difference (and we understand that there are many) depends upon the notion that, relative to their opposite-sex counterparts, males are more socialized to independence and females to interpersonal relationships. It is possible that the relative independence of men precludes the impact of emotional manipulation tactics and attempts at overinvolvement by parents, where the relative interpersonal sensitivity of women makes them more likely to feel the brunt of the emotional and psychological consequences of such tactics. Given that the sex difference did not emerge in Study 1, we offer this speculation tentatively. However, sex differences in response to parenting are a consistent part of the literature (e.g., Barrett Singer, \& Weinstein, 2000) and would be a valuable consideration for future work on narcissism development.

As a bit of a summary, it seems that healthy and unhealthy narcissism have similar, but importantly distinct, associations with parenting behavior. Healthy narcissism is associated with indulgent parenting; unhealthy narcissism is also linked with parental involvement and monitoring but is distinct in its link with psychological control (at least in females), a parenting strategy that may color a child's interpretation of a parent's support and leniency.

\section{Limitations}

We have embedded our investigation in clinical and developmental theory that predicts that parenting leads to unique outcomes in children. The current data are consistent with such a directional relation; however, the methodology of our investigation cannot rule out a number of plausible alternative explanations for our findings.

First, the project is a correlational one, and thus the reverse causal relation remains viable. Narcissistic children may engender from their parents unique parenting responses. Indeed, given the selfconfidence and high trait self-esteem that are characteristic of the healthy narcissist, one can imagine that narcissistic children may elicit from parents particularly loving responses and may, indeed, be granted more freedom and be burdened with fewer restrictions than are less narcissistic children. In a similar vein, children high in unhealthy narcissism, riddled with feelings of entitlement and privilege, may engender from their parents psychological control tactics as the parents try desperately to regulate the child's behavior. A prospective longitudinal investigation of the way in which narcissism chang- 
es as a function of parenting (or alternatively, the way parenting changes as a function of narcissism) could address these possibilities.

The project also involved only self-report of parenting and personality. Children's self-reports of parenting behavior benefit from the fact that what is documented is the child's perceptions of parental behavior, perceptions that may, indeed, be the proximal influence on (or result of) child personality and behavior. However, it is also possible that what participants perceive is not akin to reality. That is, what participants perceive as psychological control may not be intended that way, or would not be regarded that way by others. This possibility becomes a particular problem if one thinks that narcissism influences the probability that a participant will perceive a parental act as psychologically controlling, loving, or monitoring. As an example, it is possible that narcissistic children, who are chronically attuned and sensitive to interpersonal feedback, may perceive the stern look on a parent's face as an attempt at guilt induction, whereas less narcissistic children would interpret it as simple displeasure at the child's behavior, without the self-relevant emotional underpinnings. A replication of the current findings using parental reports of parenting or behavioral measures of the parenting dimensions would strengthen our confidence in the relations documented here.

\section{Conclusions and Future Directions}

Social and personality psychologists continue to mount evidence for the benefits and detriments of narcissism. Recent evidence suggests that narcissism is associated with positive psychological health (Sedikides et al., 2004). On the other hand, there are also compelling accounts of the interpersonal dysfunction and intrapersonal instability of the narcissistic self. Narcissism without trait self-esteem is associated with depression and anxiety (Watson \& Biderman, 1993; Watson, Little, \& Biderman, 1992) and may lead the narcissist to interpersonal ruin (see Baumeister et al., 1996, Bushman et al., 2003; Exline et al., 2004; Twenge \& Campbell, 2003). In light of this evidence, understanding the origins of both healthy and unhealthy narcissism has important implications as we work toward nurturing a generation of children who possess stable, positive self-regard, rather than unstable, artificial grandiosity. This project has taken an important step in the identification of links between parenting and narcissism; however, extensive work remains to be done. 
Future investigations should consider the complex nature of (1) child development as a whole and (2) factors that differentiate healthy from unhealthy development. Recent perspectives on child development have adopted a process approach, whereby development is characterized as an ongoing stream of adaptive or maladaptive responses to cultural, social, and familial influences (Cummings, Davies, \& Campbell, 2000). Subsequent investigations of narcissism development would do well to embrace this process approach and to submerge the parenting-personality relations identified in the current project within a broader developmental context, a dynamic context that includes parental personality, peer relations, and the impact of child behavior on parenting practices. A prospective, longitudinal investigation initiated from this foundation could (1) assess causal relations between parenting dimensions and personality, (2) investigate a variety of factors (e.g., parental personality, peer relations, home environment) that influence the developmental paths of narcissism and unhealthy narcissism, and (3) identify cognitive processes that mediate the various influences on personality. Until such projects are carried out, the current project provides tentative support for previous clinical theorizing regarding the development of narcissism, and we hope it will encourage the continued investigation of parenting practices as an important source of healthy and unhealthy self-regard.

\section{REFERENCES}

American Psychiatric Association. (1994). Diagnostic and statistical manual of mental disorders (4th ed). Washington, DC: Author.

Baldwin, A. L. (1955). Behavior and development in childhood. New York: Dreyden.

Barber, B. K. (1996). Parental psychological control: Revisiting a neglected construct. Child Development, 67, 3296-3319.

Barber, B. K., Olsen, J. E., \& Shagle, S. C. (1994). Associations between parental psychological control and behavioral control and youth internalized and externalized behaviors. Child Development, 65, 1120-1136.

Barrett Singer, A. T., \& Weinstein, R. S. (2000). Differential parental treatment predicts achievement and self-perceptions in two cultural contexts. Journal of Family Psychology, 14, 491-509.

Baumrind, D. (1967). Childcare practices anteceding three patterns of preschool behavior. Genetic Psychology Monographs, 75, 43-88.

Baumrind, D. (1971). Current patterns in parental authority. Developmental Psychology Monograph, 4 (1, pt. 2), 101-103. 
Baumrind, D. (1991a). The influence of parenting style on adolescent competence and substance use. Journal of Early Adolescence, 11, 56-95.

Baumrind, D. (1991b). Effective parenting during the early adolescent transition. In P. A. Cowan \& M. Hetherington (Eds.), Family transitions (pp. 111-163). Hillsdale, NJ: Erlbaum.

Baumrind, D., \& Black, A. E. (1967). Socialization practices associated with dimensions of competence and substance use. Journal of Early Adolescence, 11, 56-95.

Becker, W. C. (1964). Consequences of different kinds of parental discipline. In M. L. Hoffman \& W. W. Hoffman (Eds.), Review of child development research (Vol. 1, pp. 169-208). New York: Russell Sage Foundation.

Buri, J. R., (1991). Parental Authority Questionnaire. Journal of Personality Assessment, 57, 110-119.

Buri, J. R., Louiselle, P. A., Misukanis, T. M., \& Mueller, R. A. (1988). Effects of parental authoritarianism and authoritativeness on self-esteem. Personality and Social Psychology Bulletin, 14, 271-282.

Bushman, B. J., \& Baumeister, R. F. (1998). Threatened egotism, narcissism, selfesteem, and direct and displaced aggression: Does self-love or self-hate lead to violence? Journal of Personality and Social Psychology, 75, 219-229.

Bushman, B. J., Bonacci, A. M., Van Dijk, M., \& Baumeister, R. F. (2003). Narcissism, sexual refusal, and aggression: Testing a narcissistic reactance model of sexual coercion. Journal of Personality and Social Psychology, 84 (5), 1027 1040 .

Campbell, W. K. (1999). Narcissism and romantic attraction. Journal of Personality and Social Psychology, 77, 1254-1270.

Campbell, W. K. (2001). Is narcissism really so bad? Psychological Inquiry, 12 (4), 214-216.

Campbell, W. K., \& Foster, C. A. (2002). Narcissism and commitment in romantic relationships: An investment model analysis. Personality and Social Psychology Bulletin, 2 (4), 484-495.

Campbell, W. K., Foster, C. A., \& Finkel, E. J. (2002). Does self-love lead to love for others? A story of narcissistic game playing. Journal of Personality and Social Psychology, 83 (2), 340-354.

Campbell, W. K., Reeder, G. D., Sedikides, C., \& Elliot, A. J. (2000). Narcissism and comparative self-enhancement strategies. Journal of Research in Personality, 34, 329-347.

Clarke-Stewart, K. A. (1973). Interactions between mothers and their young children: Characteristics and consequences. Monographs of the Society for Research in Child Development, 38 (5-6, Serial No. 153).

Coolidge, F. L., Thede, L. L., \& Jang, K. L. (2001). Heritability of personality disorders in childhood: A preliminary investigation. Journal of Personality Disorders, 15 (1), 33-40.

Coopersmith, S. (1967). The antecedents of self-esteem. San Francisco: Freeman.

Crocker, J., Karpinksi, A., Quinn, D. M., \& Chase, S. K. (2003). When grades determine self-worth: Consequences of contingent self-worth for male and female engineering and psychology majors. Journal of Personality and Social Psychology, 85 (3), 507-516. 
Cummings, E. M., Davies, P. T., \& Campbell, S. B. (2000). Developmental psychopathology and family process: Theory, research, and clinical implications. New York: Guilford Press.

Emmons, R. A. (1984). Factor analysis and construct validity of the Narcissistic Personality Inventory. Journal of Personality Assessment, 48, 291-300.

Emmons, R. A. (1987). Narcissism: Theory and measurement. Journal of Personality and Social Psychology, 52, 11-17.

Exline, J. J., Baumeister, R. F., Bushman, B. J., Campbell, W. K., \& Finkel, E. J. (2004). Too proud to let go: Narcissistic entitlement as a barrier to forgiveness. Journal of Personality and Social Psychology, 87 (6), 894-912.

Gabriel, M. T., Crittelli, J. W., \& Ee, J. S. (1994). Narcissistic illusions in selfevaluations of intelligence and attractiveness. Journal of Personality, 62, 143155.

Grolnick, W. S. (2003). The psychology of parental control: How well-meant parenting backfires. Mahwah, New Jersey: Lawrence Erlbaum Associates.

Heatherton, T. F., \& Polivy, J. (1991). Development and validation of a scale for measuring state self-esteem. Journal of Personality and Social Psychology, 60, 895-910.

Herman, M. R., Dornbusch, S. M., Herron, M. C., \& Harting, J. R. (1997). The influence of family regulation, connection, and psychological autonomy on six measures of adolescent functioning. Journal of Adolescent Research, 12, 34-67.

Imbesi, L. (1999). The making of a narcissist. Clinical Social Work Journal, 27, $41-54$.

Jang, K. L., Livesley, W. J., Vernon, P. A., \& Jackson, D. N. (1996). Heritability of personality disorder traits: A twin study. Acta Psychiatrica Scandinavica, 94, 438-444.

Kernberg, O. F. (1975). Borderline conditions and pathological narcissism. New York: Jason Aronson.

Kernis, M. H. (2001). Following the trail from narcissism to fragile self-esteem. Psychological Inquiry, 12 (4), 223-225.

Kohut, H. (1977). The restoration of self. Madison, CT: International Universities Press.

Lamborn, S. D., Mounts, N. S., Steinberg, L., \& Dornbusch, S. M. (1991). Patterns of competence and adjustment among adolescents from authoritative, authoritarian, indulgent, and neglectful families. Child Development, 62, 10491065.

Loeb, R. C., Horst, L., \& Horton, P. J. (1980). Family interaction patterns associated with self-esteem in pre-adolescent girls and boys. Merrill-Palmer Quarterly, 26, 203-217.

Maccoby, E., \& Martin, J. (1983). Socialization in the context of the family: Parent-child interaction. In E. M. Hetherington (Ed.), P. H. Munsen (Series Ed.), Handbook of psychology: Vol. 4. Socialization, personality, and social development (pp. 1-101). New York: Wiley.

Millon, T. (1981). Disorders of personality. New York: Wiley.

Millon, T., \& Everly, G. (1985). Personality and its disorders: A biosocial learning approach. New York: Wiley.

Mitchell, G. (1988). The reproduction of narcissism. Women \& Therapy, 7, 35-52. 
Morf, C. C., \& Rhodewalt, F. (1993). Narcissism and self-evaluation maintenance: Explorations in object relations. Personality and Social Psychology Bulletin, 82, 668-676.

Morf, C. C., \& Rhodewalt, F. (2001). Unraveling the paradoxes of narcissism: A dynamic self-regulatory processing model. Psychological Inquiry, 12(4), 177196.

O'Brien, M. L. (1987). Examining the dimensionality of pathological narcissism: Factor analysis and construct validity of the O'Brien Multiphasic Narcissism Inventory. Psychological Reports, 61, 499-510.

Parker, G., Tupling, H., \& Brown, L. B. (1979). A parental bonding instrument. British Journal of Medical Psychology, 52, 1-10.

Patterson, G. R., \& Stouthamer-Loeber, M. (1984). The correlation of family management practices and delinquency. Child Development, 55, 1299-1307.

Paulhus, D. L. (1998). Interpersonal and intrapsychic adaptiveness of trait selfenhancement: A mixed blessing? Journal of Personality and Social Psychology, 74, 1197-1208.

Pettit, G. S., Bates, J. E., \& Dodge, K. A. (1997). Supportive parenting, ecological context, and children's adjustment: A seven-year longitudinal study. Child Development, 68, 908-923.

Ramsey, A., Watson, P. J., Biderman, M. D., \& Reeves, A. L. (1996). Self-reported narcissism and perceived parental permissiveness and authoritarianism. Journal of Genetic Psychology, 157, 227-238.

Raskin, R., \& Hall, C. S. (1979). A narcissistic personality inventory. Psychological Reports, 45, 590.

Raskin, R., \& Terry, H. (1988). A principal-components analysis of the Narcissistic Personality Inventory and further evidence of its construct validity. Journal of Personality and Social Psychology, 54, 890-902.

Rhodewalt, F., Madrian, J. C., \& Cheney, S. (1998). Narcissism, affective reactivity, and self-esteem instability: The effect of self-knowledge organization and daily experiences on daily mood. Personality and Social Psychology Bulletin, 24, 75-87.

Rhodewalt, F., \& Morf, C. C. (1998). On self-aggrandizement and anger: A temporal analysis of narcissism and affective reactions to success and failure. Journal of Personality and Social Psychology, 74 (3), 672-685.

Robins, R. W., \& Beer, J. S. (2001). Positive illusions about the self: Short-term benefits and long-term costs. Journal of Personality and Social Psychology, 80, 340-352.

Robins, R. W., \& John, O. P. (1997). Effects of visual perception and narcissism on self-perception: Is seeing believing? Psychological Science, 8 (1), 37-42.

Roe, A., \& Siegelman, M. (1963). A parent-child questionnaire. Child Development, 34, 355-369.

Rosenberg, M. (1986). Self-concept from middle childhood through adolescence. In J. Suls \& A. G. Greenwald (Eds.), Psychological perspectives on the self (Vol. 3, pp. 107-135). Hillsdale, NJ: Erlbaum.

Rothbaum, F. (1988). Maternal acceptance and child functioning. Merrill-Palmer Quarterly, 34 (2), 163-184. 
Rothstein, A. (1979). The theory of narcissism: An object-relations perspective. Psychoanalytic Review, 66, 35-47.

Schaeffer, E. S. (1965). Children's reports of parental behavior: An inventory. Child Development, 36, 413-424.

Sedikides, C., Rudich, E. A., Gregg, A. P., Kumashiro, M., \& Rusbult, C. (2004). Are normal narcissists psychologically healthy? Self-esteem matters. Journal of Personality and Social Psychology, 87 (3), 400-416.

Soucy, N., \& Larose, S. (2000). Attachment and control in family and mentoring contexts as determinants of adolescent adjustment to college. Journal of Family Psychology, 14, 125-143.

Stayton, D. J., Hogan, R., \& Ainsworth, M. D. (1971). Infant obedience and maternal behavior: The origins of socialization reconsidered. Child Development, 42, 1057-1069.

Steinberg, L. (1990). Autonomy, conflict, and harmony in the family relationship. In S. S. Feldman \& G. R. Elliot (Eds.), At the threshold: The developing adolescent (pp. 255-276). Cambridge, MA: Harvard University Press.

Steinberg, L., Elman, J. D., \& Mounts, N. S. (1989). Authoritative parenting, psychosocial maturity, and academic success among adolescents. Child Development, 60, 1424-1436.

Steinberg, L., Lamborn, S. D., Darling, N., Mounts, N. S., \& Dornbusch, S. M. (1994). Over-time changes in adjustment and competence among adolescents from authoritative, authoritarian, indulgent, and neglectful families. Child Development, 65, 754-770.

Twenge, J. M., \& Campbell, W. K. (2003). Isn't it fun to get the respect we're going to deserve? Narcissism, social rejection, and aggression. Personality and Social Psychology Bulletin, 29 (2), 261-272.

Watson, P. J., \& Biderman, M. D. (1993). Narcissistic personality inventory factors, splitting, and self-consciousness. Journal of Personality Assessment, 61, 41-57.

Watson, P. J., Grisham, S. O., Trotter, M. V., \& Biderman, M. D. (1984). Narcissism and empathy: Validity evidence for the narcissistic personality inventory. Journal of Personality Assessment, 45, 159-162.

Watson, P. J., Hickman, S. E., Morris, R. J., Milliron, J. T., \& Whiting, L. (2001). Narcissism, self-esteem, and parental nurturance. The Journal of Psychology, 129, 61-73.

Watson, P. J., Little, T., \& Biderman, M. D. (1992). Narcissism and parenting styles. Psychoanalytic Psychology, 9 (2), 231-244.

Watson, P. J., Sawrie, S. M., Green, R. L., \& Arredondo, R. (2002). Narcissism and depression: MMPI-2 evidence for the continuum hypothesis in clinical samples. Journal of Personality Assessment, 79, 85-109.

Weiss, L. A., \& Grolnick, W. S. (1991). The roles of parental involvement and support for autonomy in adolescent symptomatology. Paper presented at the biannual meeting of the Society for Research in Child Development, Seattle, WA. 